\title{
Synthesis of 5,6-Diaminoacenaphthylene by Reduction of Sterically Crowded Nitro Groups with Sodium Dithionite
}

\author{
Amber J. (Prins) Dood \\ Patrick A. Fisher \\ Christine L. Bodden \\ Luke J. Peterson \\ Kathryn A. Lindberg \\ Trevor A. Coeling \\ Douglas C. Yarbrough \\ Jason G. Gillmore* (1)
}

Department of Chemistry, Hope College, 35 East $12^{\text {th }}$ St, Holland, MI 49423, USA gillmore@hope.edu

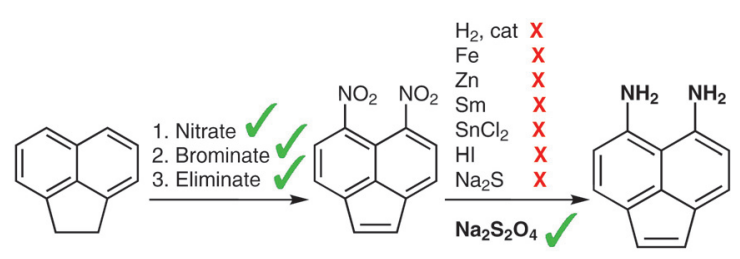

Received: 09.11.2018

Accepted after revision: 12.11.2018

Published online: 03.12 .2018

DOI: 10.1055/s-0037-1610406; Art ID: so-2018-d0056-I

License terms: cc)

Abstract 5,6-Diaminoacenaphthylene was synthesized in four steps from acenaphthene. This seemingly simple molecule provides unique synthetic challenges because it is relatively difficult to reduce the nitro groups and the molecule contains a particularly reactive double bond. It was determined that the only feasible sequence for the synthesis was to nitrate acenaphthene, then brominate, eliminate, and finally selectively reduce. Several reduction methods were attempted before finding one that would completely reduce both nitro groups while leaving the double bond intact.

Key words nitration, bromination, elimination, reduction, sodium dithionite

5,6-Diaminoacenaphthylene (DAAnl) was desired as a potentially useful building block in the synthesis of carbonyl-substituted perimidinespirohexadienones (PSHDs) $)^{1,2}$ previously pursued in our group (Scheme 1 ).

Initially we intended to couple carbonyl-substituted 1,8-diaminonaphthalenes to 2,6-di-tert-butylbenzoquinone (DBB) to synthesize carbonyl-substituted PSHDs. However, on attempted coupling of 1,8-diaminonaphthalic anhydride (or its alkyl imides) ${ }^{3-5}$ with DBB, the carbonyl electron-withdrawing groups rendered the amino groups entirely non-nucleophilic and no reaction occurred (Scheme 1, top). Thus, we concluded that the carbonyls would need to be installed after coupling. We proposed that either 5,6-diaminoacenaphthene (DAAn) or 5,6-diaminoacenaphthylene (DAAnl) could be coupled with DBB to form a PSHD analogue that could then be oxidized to a carbonylsubstituted PSHD. We were able to successfully synthesize 5,6-diaminoacenaphthene (DAAn) in high yield and purity in two steps from acenaphthene (An). ${ }^{6}$ However, coupling

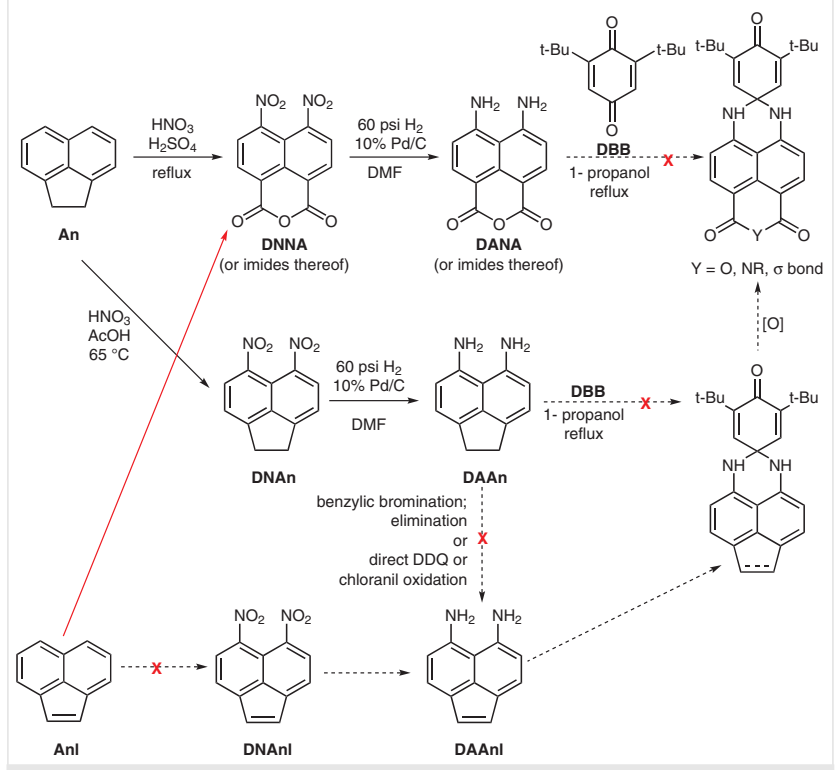

Scheme 1 Proposed routes to carbonyl-substituted PSHDs

with DBB failed, instead yielding the reduction product of DBB, 2,6-di-tert-butylhydroquinone, and polymeric byproducts (Scheme 1, middle). We presumed that this was due to the easily abstractable benzylic hydrogens on DAAn. Thus, we realized that DAAnl (clearly much less readily oxidized) would be required for coupling, to avoid reducing DBB. Unfortunately, this deceptively simple molecule had not been previously reported.

Having previously prepared DAAn (Scheme 1 , middle), we attempted benzylic bromination, in order to subsequently eliminate to the desired DAAnl. However, we found that it was not possible to brominate DAAn at the desired position with either $\mathrm{N}$-bromosuccinimide (NBS) or molecular bromine, perhaps because the dark color of the com- 
pound in solution precluded photoinitiation of the free radical benzylic bromination. We also attempted direct oxidation of DAAn to DAAnl with chloranil and 2,3-dichloro-5,6dicyano-1,4-benzoquinone (DDQ) to no avail.

Next, we turned to acenaphthylene (Anl) as a starting material, so as not to have to install the double bond ourselves. Our intent was to doubly nitrate and then reduce to our desired DAAnl, as we had done to obtain DAAn from acenaphthene. Unfortunately, the double bond in acenaphthylene proved too reactive. Conditions could not be found that would doubly nitrate acenaphthylene without concomitantly oxidizing it to yield 1,8-dinitronaphthalic anhydride (DNNA) (Scheme 1, bottom and red arrow).

This persuaded us that the only practical sequence for the synthesis would be to nitrate acenaphthene (An), then install the double bond via bromination ${ }^{8,9}$ and elimination, ${ }^{9,10}$ and finally reduce the nitro groups to amino groups (Scheme 2). This seemed entirely reasonable, as aromatic nitro groups can generally be reduced selectively in the presence of olefins by several methods. Unfortunately, the first several methods we employed to reduce dinitroacenaphthylene (DNAnl) to DAAnl were unsuccessful. The nitro groups could not be reduced without also reducing the double bond, even with several different reduction methods, including ones known to successfully reduce $p$-nitrostyrene to $p$-aminostyrene. ${ }^{11}$ These failed methods are outlined in Table 1 . In all cases in which any reduction of the nitro groups occurred, it was accompanied by either substantial or complete reduction of the olefin.

We hypothesized that the highly reactive double bond of acenaphthylene and dinitroacenaphthylene was to blame for these results. We also hypothesized that the sterically crowded nitro groups in dinitroacenaphthylene were likely rotated out of plane relative to the arene and were thus not typical of 'nitroarenes' for which this reduction is usually so

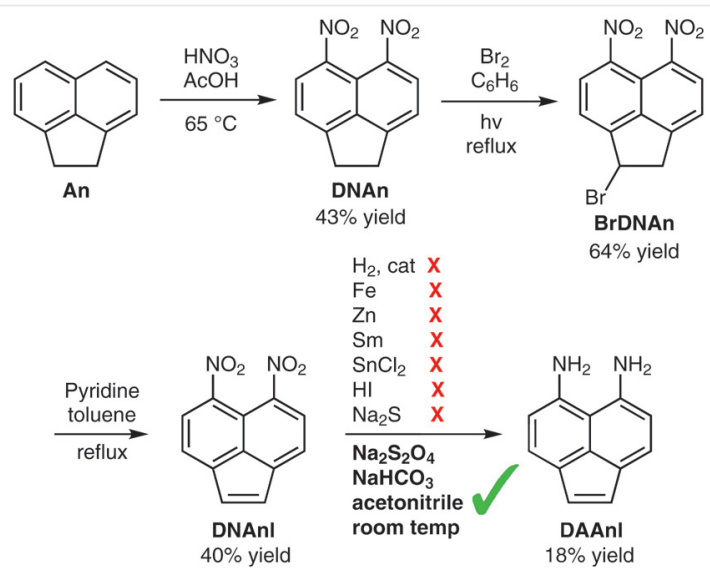

Scheme 2 Synthesis of 5,6-diaminoacenaphthylene

facile. Computations ${ }^{21-25}$ confirmed our geometric hypothesis. The nitro groups are rotated 41 degrees relative to the arene. Moreover the nitrogens are pushed out of plane with the arene, with an unconventional dihedral angle between $\mathrm{N}-\mathrm{C} 5-\mathrm{C} 6-\mathrm{N}$ of 22 degrees; i.e., one $\mathrm{N}$ is roughly 11 degrees above the plane of the arene and the other 11 degrees below the plane. Beyond our geometric hypothesis, molecular orbital calculations show very little frontier orbital (HOMO or LUMO) density on the nitro groups in DNAnl, with high coefficients in the bonding (HOMO) and antibonding (LUMO) interaction of the olefin. In nitrostyrene, for comparison, the nitro group and the olefin are both coplanar (all dihedrals < 0.5 degrees) with the benzene ring and, while the HOMO has low coefficients on the nitro group, the LUMO has its highest coefficients on the nitro groups. Figure 1 shows the differences between DNAnl and nitrostyrene in both geometry and frontier orbitals.

Table 1 Failed Reduction Attempts

\begin{tabular}{|c|c|c|}
\hline Reductant & Ref. & Result \\
\hline $\mathrm{H}_{2}(20-60 \mathrm{psi}), 5 \%$ or $10 \% \mathrm{Pd} / \mathrm{C}$, EtOAc or DMF & 12 & over-reduction, ${ }^{\mathrm{a}}$ or mixed reduction if stopped before completion \\
\hline $\mathrm{H}_{2}$ (70 psi), Lindlar's cat, DMF & 13 & no reaction \\
\hline $\mathrm{Fe}, \mathrm{AcOH}$ & 2 & over-reduction $^{\mathrm{a}}$ \\
\hline $\mathrm{Fe}, \mathrm{HCl}$ & 11 & over-reduction $^{\mathrm{a}}$ \\
\hline $\mathrm{Zn}, \mathrm{CaCl}_{2}, \mathrm{EtOH}$ & 14 & incomplete reduction mixtures ${ }^{\mathrm{b}}$ \\
\hline $\mathrm{Zn}, \mathrm{NaOH}, \mathrm{EtOH}$ & 15 & incomplete reduction mixtures ${ }^{\mathrm{b}}$ \\
\hline Sm & 16 & no reaction \\
\hline $\mathrm{SnCl}_{2}, \mathrm{HCl}$ & 17 & over-reduction $^{\mathrm{a}}$ at elevated temperatures; incomplete reduction mixtures ${ }^{\mathrm{b}}$ at lower temperatures \\
\hline $\mathrm{SnCl}_{2}, \mathrm{EtOH}$ & 18 & minimal incomplete reduction \\
\hline $\mathrm{HI}$ & 19 & incomplete reduction (+ $\mathrm{HI}$ addn) \\
\hline $\mathrm{Na}_{2} \mathrm{~S}$ & 20 & intractable mixtures, minimal redn \\
\hline
\end{tabular}

\footnotetext{
a Diaminoacenaphthene was major product by GC/MS (confirmed by ${ }^{1} \mathrm{H}$ NMR in some cases).
}

b Substantial reduction of olefin detected by GC/MS before both nitro groups were reduced. 


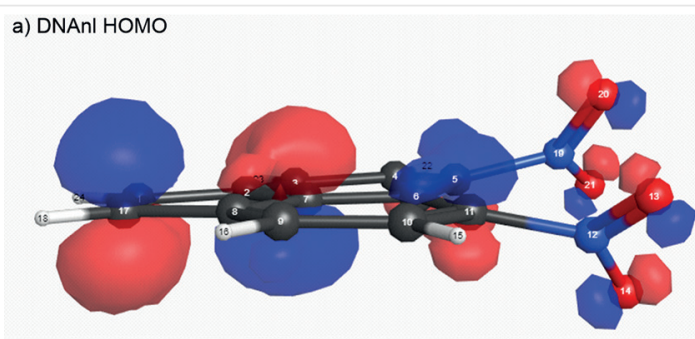

b) DNAnI LUMO

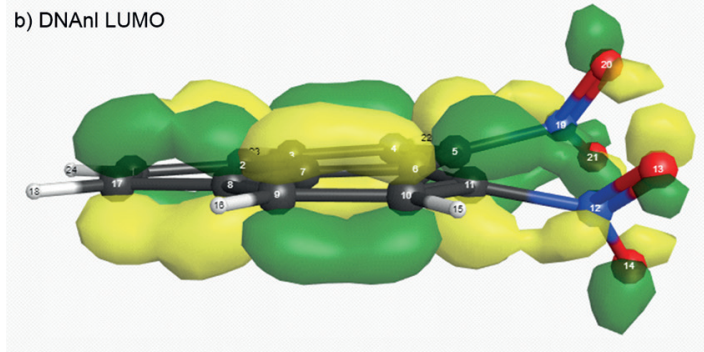

c) Nitrostyrene HOMO

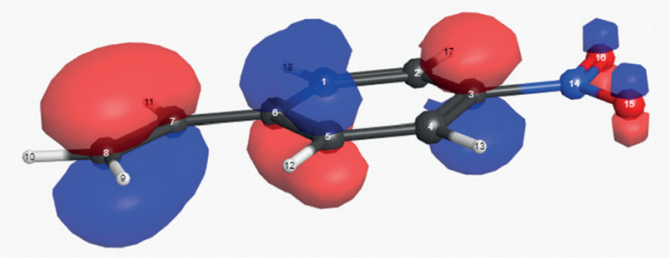

d) Nitrostyrene LUMO

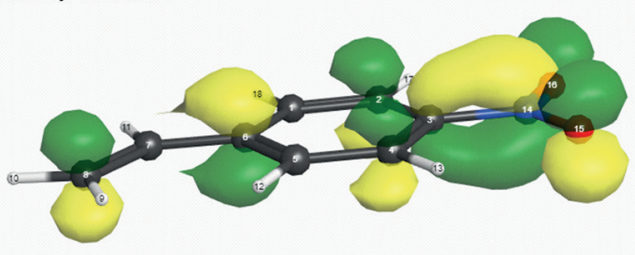

Figure 1 Computed geometries and frontier orbitals of DNAnl and nitrostyrene

Serendipitously, years later, after having tried a sodium dithionite reduction ${ }^{26}$ in other work, we realized it was one reductant we had never tried in our attempts to reduce DNAnl to DAAnl. Remarkably, it worked, to cleanly (albeit in low yield) give the selective reduction we desired. ${ }^{27}$ We note that the title compound is expected to be in the 'Proton Sponge ${ }^{\mathbb{\otimes} \cdot 28}$ family of compounds and, in our hands, care must be taken to avoid forming insoluble complexes in the presence of metal ions or even weak acids. This, or possibly oxidation to dark insoluble species, may have been the cause of the low yield in the ultimate step.

We admittedly do not report any particularly novel reactions or conditions. Nor do we have any particular insight into why dithionite was the silver bullet for this successful oxidation. We do not have any plans to immediately resume work toward carbonyl-substituted PSHDs now that we have prepared DAAnl. Nevertheless, we find it informative to report our synthesis of this deceptively simple target and al- low others the opportunity to learn from our experiences, both generally and specifically to have access to DAAnl as a potential starting material or intermediate in other syntheses. While yields were low (2.0\% over four steps), the acenaphthene starting material is very inexpensive and no purification was required at any point in the synthesis.

\section{Funding Information}

This work was supported in part by: NSF CAREER (CHE-0952768), NSF REU (CHE-0243828 \& CHE-0851194), NSF STEM-ENGINES URC (CHE-0629174), a Henry Dreyfus Teacher-Scholar Program award to J.G.G., an HHMI Scholar award to C.L.B. and J.G.G. by a grant to Hope College by the Howard Hughes Medical Institute through the Undergraduate Science Education Program, and the Hope College Chemistry Department's Schaap Research Fellows program and Undergraduate Research Fund. The MU3C ${ }^{21,22}$ cluster was supported by NSF MRI (CHE-0520704 \& CHE-1039925).

\section{Acknowledgment}

The authors gratefully acknowledge: Dr. Dan Henton (MSU St. Andrews) for the suggestion to try dithionite; Mr. Eric Webb (former JGG group member) for running NMRs for A.J.P.; Professors Jeff Johnson \& Traci Smith for mentoring A.J.P. and P.A.F., respectively, on CHEM $256 B^{29}$ projects related to this research; Prof. Dan Stanford (Harper College) for initial research mentoring of D.C.Y. and C.L.B. through the NSF STEM-ENGINES URC; and Dr. Mike Walla (University of South Carolina) for HRMS measurement.

\section{Supporting Information}

${ }^{1} \mathrm{H}$ NMR and GC/MS data for the four-step synthesis of the title compound, and raw output files for the molecular orbital calculations in Figure 1 are provided. Supporting information for this article is available online at https://doi.org/10.1055/s-0037-1610406.

\section{References and Notes}

(1) Minkin, V. I.; Komissarov, V. N.; Kharlanov, V. A. In Organic Photochromic and Thermochromic Compounds Vol. 1; Crano, J. C.; Guglielmetti, R. J., Ed.; Plenum: New York, 1999, 315.

(2) Moerdyk, J. P.; Speelman, A. L.; Kuper, K. E. III; Heiberger, B. R.; Ter Louw, R. P.; Zeller, D. J.; Radler, A. J.; Gillmore, J. G. J. Photochem. Photobiol. A 2009, 205, 84.

(3) Jones, L. A.; Joyner, C. T.; Kim, H. K.; Kyff, R. A. Can. J. Chem. 1970, 48, 3132.

(4) Duda-Johner, S.; Daib, J. O.; Mohr, K.; Tacke, R. J. Organomet. Chem. 2003, 686, 75.

(5) Zhu, M.; Zhang, J.; Yu, G.; Chen, H.; Huang, J.; Liu, Y. Chem. Asian J. 2012, 7, 2208

(6) Ozeryanskii, K. A.; Pozharskii, A. F. Russ. Chem. Bull. 2000, 49, 1399.

(7) 5,6-Dinitroacenaphthene (DNAn) (ref. 3): Acenaphthene (39.9 $\mathrm{g}, 259 \mathrm{mmol}$ ) was dissolved in glacial acetic acid $(500 \mathrm{~mL})$. Fuming nitric acid $(100 \mathrm{~mL})$ was added dropwise via addition funnel while the flask was submerged in an ice bath. After the addition was complete, the flask was removed from the ice bath and placed in an oil bath set to $65^{\circ} \mathrm{C}$. The reaction was stirred with heating for 6 hours and then allowed to cool to room tem- 
perature. The precipitated solid was collected on a medium frit and washed with water $(4 \times 50 \mathrm{~mL})$, then dried under vacuum overnight. Yield: $27.3 \mathrm{~g}$ (43\%); yellow solid. ${ }^{1} \mathrm{H}$ NMR (400 MHz, $\left.\mathrm{CDCl}_{3}\right): \delta=8.29$ (d, $2 \mathrm{H}$ ), 7.51 (d, $\left.2 \mathrm{H}\right), 3.58$ (s, $4 \mathrm{H}$ ). GC/MS: $m / z=244$ (parent ion), 139 (base peak).

(8) 1-Bromo-5,6-dinitroacenaphthene (BrDNAn) (ref. 9): DNAn $(11.58 \mathrm{~g}, 47.4 \mathrm{mmol})$ was dissolved in benzene $(1000 \mathrm{~mL})$ and stirred. $\mathrm{Br}_{2}(7.5 \mathrm{~g}, 47 \mathrm{mmol})$ in benzene $(100 \mathrm{~mL})$ was added dropwise to the flask with vigorous stirring. Throughout the addition and subsequent reaction, four $200 \mathrm{~W}$ incandescent lightbulbs were used to irradiate the reaction flask. Irradiation provided substantial heating, but a heating mantle was used to assure reflux was maintained for seven hours after addition was complete. The reaction was allowed to cool to room temperature and then transferred to a separatory funnel and washed with water $(500 \mathrm{~mL})$. The organic layer was dried over calcium chloride and gravity filtered. Solvent was removed by rotary evaporation. Yield: $9.78 \mathrm{~g}(64 \%)$; pale-brown solid. ${ }^{1} \mathrm{H}$ NMR $\left(400 \mathrm{MHz}, \mathrm{CDCl}_{3}\right): \delta=8.37(\mathrm{~d}, 1 \mathrm{H}), 8.35(\mathrm{~d}, 1 \mathrm{H}), 7.76(\mathrm{~d}, 1 \mathrm{H})$, 7.57 (d, $1 \mathrm{H}), 5.89$ (d, $1 \mathrm{H}), 4.29$ (dd, $1 \mathrm{H}), 3.93$ (d, $1 \mathrm{H}) . \mathrm{GC} / \mathrm{MS}$ showed dehydrohalogenation in the injector port, giving the identical pattern and same retention time as observed for DNAnl (ref. 10): MS: $m / z=242$ (parent ion), 138 (base peak).

(9) Usachenko, V. G. Zh. Org. Khim. 1985, 21, 1303.

(10) 5,6-Dinitroacenaphthylene (DNAnl) (ref. 9): BrDNAn (13.7 g, $42.4 \mathrm{mmol})$ was dissolved in toluene $(100 \mathrm{~mL})$ and pyridine $(100 \mathrm{~mL})$. The solution was heated to reflux for three hours, with stirring. The reaction was allowed to cool to room temperature, and solvents were removed by rotary evaporation. The resulting solids were stirred in chloroform $(70 \mathrm{~mL})$ for 10 minutes, then vacuum filtered through a medium frit. This chloroform extraction of the solids was repeated four more times. The combined chloroform extracts were washed with $\mathrm{HCl}$ (ca. $300 \mathrm{~mL}$ ) and then brine (ca. $350 \mathrm{~mL}$ ). The organic layer was dried over sodium sulfate and then gravity filtered. Rotary evaporation of the chloroform extracts yielded a brown solid (4.11 g, 40\%). ${ }^{1} \mathrm{H}$ NMR $\left(400 \mathrm{MHz}, \mathrm{CDCl}_{3}\right): \delta=8.15$ (d, $\left.2 \mathrm{H}\right), 7.67$ (d, $2 \mathrm{H}), 7.12$ (s, $2 \mathrm{H}) ;{ }^{1} \mathrm{H}$ NMR (400 MHz DMSO- $\left.d_{6}\right): \delta=8.39$ (d, $2 \mathrm{H}$ ), 7.99 (d, $2 \mathrm{H}$ ), 7.35 (s, $2 \mathrm{H}$ ). GC/MS: $m / z=242$ (parent ion), 138 (base peak); an identical pattern at the same retention time as was observed for BrDNAnl (ref. 8).

(11) Lin, Z.-M.; Zheng, C.; Xiao, J.-J.; Chen, R.-F.; Zhao, P.; Song, J.; An, Z.-F.; Tian, H.; Huang, W. New J. Chem. 2012, 36, 1512.

(12) Manabe, K.; Okamura, K.; Date, T.; Koga, K. J. Org. Chem. 1993, $58,6692$.

(13) Evans, D. A.; Miller, S. J.; Ennis, M. D. J. Org. Chem. 1993, 58, 471.

(14) Sundberg, R. J.; Pitts, W. J. J. Org. Chem. 1991, 56, 3048.

(15) Martin, E. L. Org. Synth., Coll. Vol. 2 1943, 501

(16) Yu, C.; Liu, B.; Hu, L. J. Org. Chem. 2001, 66, 919.

(17) Buck, J. S.; Ides, W. S. Org. Synth., Coll. Vol. 2 1943, 130.

(18) Ling, C.; Lahti, P. M. J. Am. Chem. Soc. 1994, 116, 8784.

(19) Kumar, J. S. D.; Ho, M.-K. M.; Toyokuni, T. Tetrahedron Lett. 2001, $42,5601$.

(20) Somashekarappa, M. P.; Keshavayya, J.; Sampath, S. Pure Appl. Chem. 2002, 74, 1609.

(21) Computations were performed with the Midwest Undergraduate Computational Chemistry Consortium Cluster housed at Hope College (ref. 22), using density functional theory with the B3LYP hybrid functional (ref. 23) and 6-311+G(2d,p) basis set in vacuo implemented using Gaussian (ref. 24) accessed via the WebMO (ref. 25) web-based graphical user interface.

(22) Kuwata, K. T.; Krueger, B. P.; Kohen, D.; Polik, W. F. CUR Quarterly 2012, 32, 9; https://www.cur.org/what/publications/journals/curq/issues/ (accessed October 2, 2018).
(23) (a) Becke, A. D. J. Chem. Phys. 1996, 104, 1040. (b) Becke, A. D. Phys. Rev. A 1988, 38, 3098. (c) Lee, C.; Yang, W.; Parr, R. G. Phys. Rev. B 1988, 37, 785.

(24) (a) Gaussian09 (ref. 24c) was used for geometries and Gaussian16 (ref. 24b) for molecular orbital calculations (b) Frisch, M. J.; Trucks, G. W.; Schlegel, H. B.; Scuseria, G. E.; Robb, M. A.; Cheeseman, J. R.; Scalmani, G.; Barone, V.; Petersson, G. A.; Nakatsuji, H.; Li, X.; Caricato, M.; Marenich, A. V.; Bloino, J.; Janesko, B. G.; Gomperts, R.; Mennucci, B.; Hratchian, H. P.; Ortiz, J. V.; Izmaylov, A. F.; Sonnenberg, J. L.; Williams-Young, D.; Ding, F.; Lipparini, F.; Egidi, F.; Goings, J.; Peng, B.; Petrone, A.; Henderson, T.; Ranasinghe, D.; Zakrzewski, V. G.; Gao, J.; Rega, N.; Zheng, G.; Liang, W.; Hada, M.; Ehara, M.; Toyota, K.; Fukuda, R.; Hasegawa, J.; Ishida, M.; Nakajima, T.; Honda, Y.; Kitao, O.; Nakai, H.; Vreven, T.; Throssell, K.; Montgomery, J. A. Jr.; Peralta, J. E.; Ogliaro, F.; Bearpark, M. J.; Heyd, J. J.; Brothers, E. N.; Kudin, K. N.; Staroverov, V. N.; Keith, T. A.; Kobayashi, R.; Normand, J.; Raghavachari, K.; Rendell, A. P.; Burant, J. C.; Iyengar, S. S.; Tomasi, J.; Cossi, M.; Millam, J. M.; Klene, M.; Adamo, C.; Cammi, R.; Ochterski, J. W.; Martin, R. L.; Morokuma, K.; Farkas, O.; Foresman, J. B.; Fox, D. J. Gaussian 16, Revision B.01; Gaussian, Inc: Wallingford CT, 2016. (c) Frisch, M. J.; Trucks, G. W.; Schlegel, H. B.; Scuseria, G. E.; Robb, M. A.; Cheeseman, J. R.; Scalmani, G.; Barone, V.; Mennucci, B.; Petersson, G. A.; Nakatsuji, H.; Caricato, M.; Li, X.; Hratchian, H. P.; Izmaylov, A. F.; Bloino, J.; Zheng, G.; Sonnenberg, J. L.; Hada, M.; Ehara, M.; Toyota, K.; Fukuda, R.; Hasegawa, J.; Ishida, M.; Nakajima, T.; Honda, Y.; Kitao, O.; Nakai, H.; Vreven, T.; Montgomery, J. A. Jr.; Peralta, J. E.; Ogliaro, F.; Bearpark, M.; Heyd, J. J.; Brothers, E.; Kudin, K. N.; Staroverov, V. N.; Kobayashi, R.; Normand, J.; Raghavachari, K.; Rendell, A.; Burant, J. C.; Iyengar, S. S.; Tomasi, J.; Cossi, M.; Rega, N.; Millam, J. M.; Klene, M.; Knox, J. E.; Cross, J. B.; Bakken, V.; Adamo, C.; Jaramillo, J.; Gomperts, R.; Stratmann, R. E.; Yazyev, O.; Austin, A. J.; Cammi, R.; Pomelli, C.; Ochterski, J. W.; Martin, R. L.; Morokuma, K.; Zakrzewski, V. G.; Voth, G. A.; Salvador, P.; Dannenberg, J. J.; Dapprich, S.; Daniels, A. D.; Farkas, Ö.; Foresman, J. B.; Ortiz, J. V.; Cioslowski, J.; Fox, D. J. Gaussian 09, Revision D.01; Gaussian, Inc: Wallingford CT, 2013.

(25) Schmidt, J. R.; Polik, W. F. WebMO Enterprise, versions 17.0.012e and 18.01.001e; WebMO LLC: Holland, MI, 2017, available from http //www.webmo.net (accessed October 12, 2018).

(26) Khurana, J. M.; Singh, S. J. Indian Chem. Soc. 1996, 73, 487.

(27) 5,6-Diaminoacenaphthylene (DAAnl): DNAnl $(0.50 \mathrm{~g}, 2.06$ $\mathrm{mmol}$ ) was dissolved in acetonitrile $(300 \mathrm{~mL})$. Sodium dithionite $(2.14 \mathrm{~g}, 12.3 \mathrm{mmol})$ and sodium bicarbonate $(2.09 \mathrm{~g}, 24.9$ $\mathrm{mmol}$ ) were added to the solution and dissolved with the addition of water $(200 \mathrm{~mL})$. The mixture was allowed to stir gently under nitrogen at room temperature for 40 hours. The reaction mixture was diluted with water $(1300 \mathrm{~mL})$ and extracted with ethyl acetate $(5 \times 200 \mathrm{~mL})$. The organic extracts were dried with anhydrous potassium carbonate, filtered, and rotary evaporated to yield a brown solid (68.6 mg, 18\%). ${ }^{1} \mathrm{H}$ NMR (400 MHz, DMSO- $\left._{6}\right): \delta=7.43(\mathrm{~d}, 2 \mathrm{H}), 6.70(\mathrm{~s}, 2 \mathrm{H}), 6.64(\mathrm{~d}, 2 \mathrm{H}), 5.87$ (broad s, $4 \mathrm{H}$ ); GC/MS: $m / z=182$ (parent ion, base peak). HRMS: $\mathrm{m} / z$ calcd for $\mathrm{C}_{12} \mathrm{H}_{10} \mathrm{~N}_{2}: 182.0844$; found: 182.0846 (error $<1.1$ $\mathrm{ppm})$.

(28) (a) Staab, H. A.; Saupe, T. Angew. Chem. Int. Ed. Engl. 1988, 27, 865. (b) Registered trademark of Sigma-Aldrich, catalog \#158496, www.sigmaaldrich.com/catalog/product/aldrich/158496 (accessed October 17, 2018)

(29) Smith, T. L.; Gillmore, J. G.; Scogin, S. C. Chem. Educ. 2017, 22, 177. 